\title{
Digital subtraction angiography findings and population demographics of patients with subarachnoidal haemorrhage and subsequent causative aneurysms at Universitas Academic Hospital, Bloemfontein
}

\begin{tabular}{|c|c|}
\hline \multicolumn{2}{|c|}{$\begin{array}{l}\text { Authors: } \\
\text { Ambrosius Swartbooi }^{1} \\
\text { Carin Meyer } \\
\text { Coert de Vries }^{1}\end{array}$} \\
\hline \multicolumn{2}{|c|}{$\begin{array}{l}\text { Affiliation: } \\
{ }^{1} \text { Department of Clinical } \\
\text { Imaging Sciences, Universitas } \\
\text { Academic Hospital, } \\
\text { Bloemfontein, South Africa }\end{array}$} \\
\hline \multicolumn{2}{|c|}{$\begin{array}{l}\text { Research Project no.: } \\
\text { ECUFS NR 32/2014 }\end{array}$} \\
\hline \multicolumn{2}{|c|}{$\begin{array}{l}\text { Corresponding author: } \\
\text { Ambrosius Swartbooi, } \\
\text { broman31@hotmail.com }\end{array}$} \\
\hline \multicolumn{2}{|c|}{$\begin{array}{l}\text { Dates: } \\
\text { Received: } 06 \text { May } 2016 \\
\text { Accepted: } 27 \text { Sept. } 2016 \\
\text { Published: } 22 \text { Nov. } 2016\end{array}$} \\
\hline \multicolumn{2}{|c|}{$\begin{array}{l}\text { How to cite this article: } \\
\text { Swartbooi A, Meyer C, De } \\
\text { Vries C. Digital subtraction } \\
\text { angiography findings and } \\
\text { population demographics of } \\
\text { patients with subarachnoidal } \\
\text { haemorrhage and } \\
\text { subsequent causative } \\
\text { aneurysms at Universitas } \\
\text { Academic Hospital, } \\
\text { Bloemfontein. S Afr J Rad. } \\
\text { 2016;20(1), a1030. http:// } \\
\text { dx.doi.org/10.4102/sajr. } \\
\text { v20i1.1030 }\end{array}$} \\
\hline \multicolumn{2}{|c|}{$\begin{array}{l}\text { Copyright: } \\
\text { (c) 2016. The Authors. } \\
\text { Licensee: AOSIS. This work } \\
\text { is licensed under the } \\
\text { Creative Commons } \\
\text { Attribution License. }\end{array}$} \\
\hline \multicolumn{2}{|l|}{ Read online: } \\
\hline 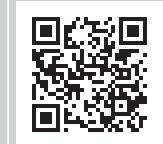 & $\begin{array}{l}\text { Scan this QR } \\
\text { code with your } \\
\text { smart phone or } \\
\text { mobile device } \\
\text { to read online. }\end{array}$ \\
\hline
\end{tabular}

Background: Subarachnoid haemorrhage (SAH) secondary to aneurysmal rupture may be associated with serious neurological sequelae or even mortality. According to international literature, only aneurysms $>7 \mathrm{~mm}$ or aneurysms in the posterior circulation require treatment. Retrospective single-centre studies have, however, disputed this after demonstrating that the average size of ruptured aneurysms are $<7 \mathrm{~mm}$. More recent guidelines place less emphasis on size and more on associated risk factors.

Objectives: The aim of this investigation was to assess the aneurysm characteristics and demographics of patients who presented to our institution with SAH secondary to an aneurysm detected at digital subtraction angiography (DSA).

Method: A retrospective descriptive study was conducted. Patients who presented with SAH over a 6-year period, from 2008 to 2013, were included. The average size of the intracranial aneurysms at the time of rupture was analysed. Data about aneurysm characteristics and patient demographics were obtained from patient files. Data were analysed by the researchers with assistance from the Department of Biostatistics.

Results: In total, 161 of 374 patients who underwent DSA had ruptured aneurysms. Most patients were women with ages ranging from 18 to 73 years (mean 45 years). The mean size of aneurysms were $5.8 \mathrm{~mm}$ (range $1.2 \mathrm{~mm}-20 \mathrm{~mm}$ ), with $74.5 \%$ of aneurysms $<7 \mathrm{~mm}$. Most aneurysms were noted involving the anterior circulation (72\%), with the majority arising from the anterior communicating artery (36.7\%).

Conclusion: We found that aneurysms rupture at sizes $<7 \mathrm{~mm}$ and are commonly located in the anterior circulation. Our findings emphasise the importance of conducting institutional reviews to consider adapting international treatment guidelines for the local South African situation.

\section{Introduction}

Subarachnoid haemorrhage (SAH) secondary to aneurysmal rupture affects 10-15 per 100000 of the Western population per year. ${ }^{1}$ Aneurysmal SAH is a serious condition with mortality rates approaching $50 \%$, and with $30 \%$ of survivors suffering moderate-to-severe neurological disability. ${ }^{2,3}$

Literature originating mainly from the International Study of Unruptured Intracranial Aneurysms (ISUIA) advocated treatment of aneurysms $>7 \mathrm{~mm}$, or those in the posterior circulation, because of the lesser risk of rupture of those that are $<7 \mathrm{~mm}$ and in the anterior circulation..$^{2,4}$ In the prospective ISUIA (2003), aneurysmal annual rupture risk for anterior circulation lesions in patients without prior SAH was cited as $0.1 \%$ for aneurysms $<7 \mathrm{~mm} .^{2}$ Analysis performed by Morita et al. in 2005 found an overall rupture risk of 2.7\% [95\% confidence interval (CI) $2.2 \%-$ $3.3 \%$ ] - higher than that reported by ISUIA, which reported an overall rupture risk of $0.3 \%$ (95\% CI $0.2 \%-0.4 \%)$ in 1998 and $0.8 \%(95 \%$ CI $0.6 \%-1.0 \%)$ in $2003 .{ }^{5}$

Several single-centre reviews have been published reporting that the average size of a ruptured intracranial aneurysm is significantly $<7 \mathrm{~mm}$ and that the annual rupture risk is between $0.5 \%$ and $2.7 \%{ }^{5,6,7}$ The reported critical diameter at which the incidence of aneurysm rupture increases is between $4 \mathrm{~mm}$ and $10 \mathrm{~mm}^{7}$ 
Aneurysm location is another point of contention. Multiple studies pointed out that the majority of ruptured aneurysms involve the circle of Willis and anterior circulation. ${ }^{1,3,7}$ This finding is contrary to ISUIA data, McNulty et al. and Morita et al., all of which concluded that posterior circulation aneurysms are at greater risk of rupture..$^{2,4,5}$

Recently published management guidelines by Steiner et al. in 2013 and Thompson et al. in 2015 concluded that apart from size and location, other risk factors for aneurysm rupture should be taken into consideration when deciding to treat or observe unruptured intracranial aneurysms. These include aneurysm configuration and morphology, documented growth, female gender, younger age, current smoking history, hypertension and prior personal and family history of aneurysmal SAH. ${ }^{8,9}$ The role of smoking is postulated to involve weakening of vessel walls and increase in blood pressure. ${ }^{6,10}$

Although hypertension is implicated in the development of intracranial aneurysms, it has not been found to cause aneurysm rupture. This lack of evidence does not infer that patients with untreated or suboptimal control of hypertension may not suffer aneurysm rupture..$^{10}$

Overall, there are limited published data on the topic of aneurysm size at rupture in the South African context. However, Blignaut et al. found human immunodeficiency virus (HIV) infection to be an important comorbid condition concerning aneurysm morphology, younger patient age and a smaller average aneurysm rupture size than that of the general population in another study conducted at Universitas Academic Hospital. ${ }^{11}$ Although this study does not differentiate between
HIV-infected and HIV-uninfected individuals, further local research is warranted to determine how the local aneurysm characteristics and affected patient profiles correlate with the recommended international guidelines.

\section{Objectives}

The aim of this investigation was to assess the aneurysm characteristics and demographics of patients presenting at Universitas Academic Hospital with SAH and a subsequent causative aneurysm detected at digital subtraction angiography (DSA).

\section{Methodology}

A retrospective, descriptive, observational study was performed on all patients who underwent cerebral DSA at Universitas Academic Hospital Complex (a large referral hospital offering neurovascular services to central South Africa) between 01 January 2008 and 31 December 2013.

Approval for the study was obtained from the Ethics Committee of the Faculty of Health Sciences of the University of the Free State.

The equipment that were used for the cerebral DSA examinations during the 6-year period were the Siemens Multistar, Axiom Artis or Philips Allura XPER FD 20/20 angiography unit.

Only patients in whom SAH had been detected on computed tomography, and a subsequent causative aneurysm was demonstrated at DSA, were included in the study (Figure 1).

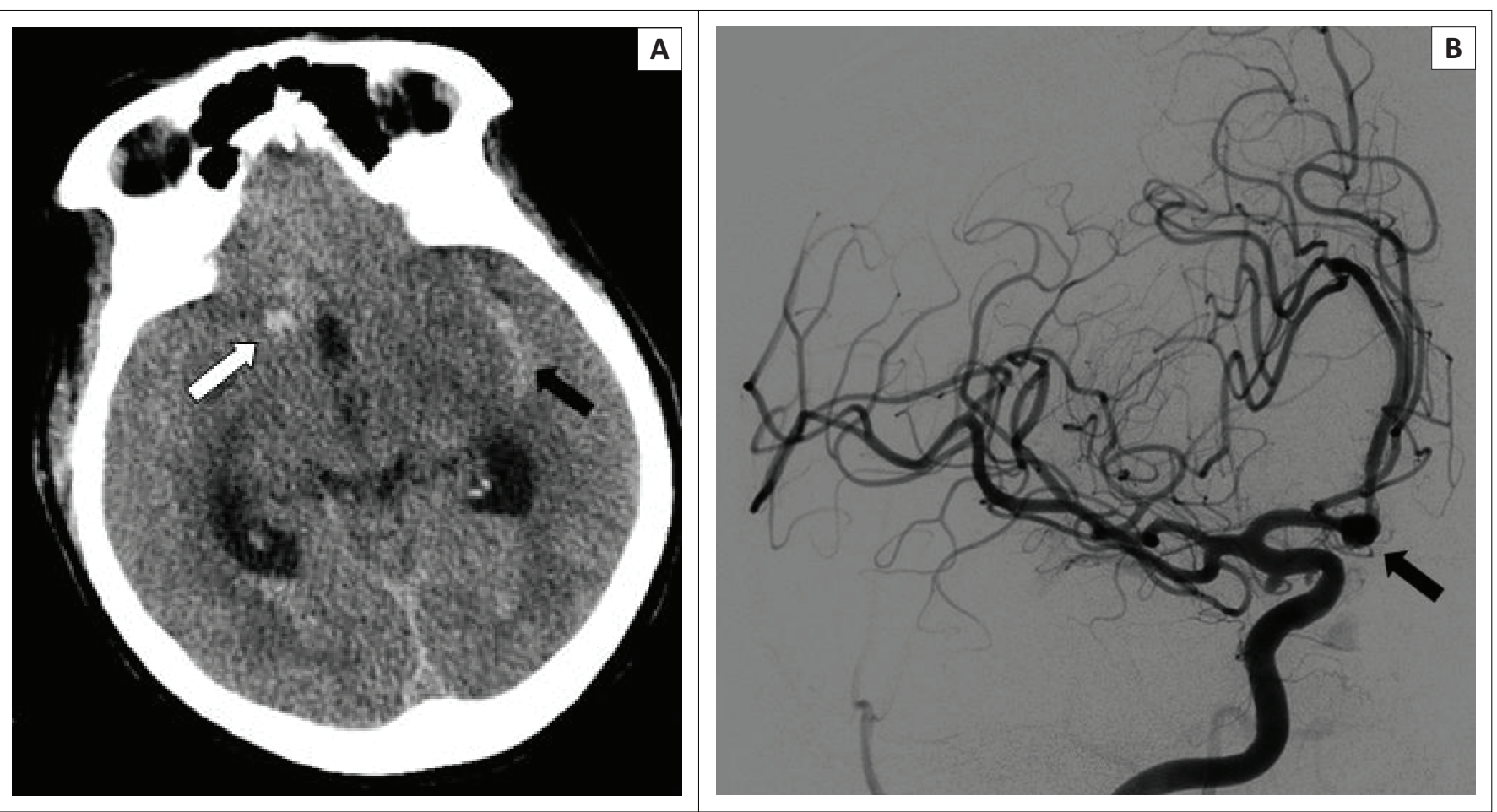

FIGURE 1: (a) Subarachnoidal haemorrhage in the left sylvian fissure (black arrow) and focal haemorrhage to the right of the third ventricle (white arrow) on precontrast computed tomographic scan; (b) Digital subtraction angiography demonstrates anterior communicating artery aneurysm (black arrow). 
Patients with SAH detected on computed tomography, but no subsequent DSA, were excluded from the study. Procedures performed for indications other than aneurysmrelated SAH were also excluded from the study.

Patients' demographic information was gathered from patient files and the hospital's electronic information server. Data regarding imaging findings for the aneurysms were obtained from the Universitas Hospital Picture Archive Communication System for recent data (20102013) and the hospital information system for older data (pre-2010). Imaging findings for aneurysms were obtained from radiology reports, which included the largest diameter, aneurysm neck to size ratio and aneurysm location.

Standard DSA views used were as follows: antero-posterior, left anterior oblique $20^{\circ}$, right anterior oblique $20^{\circ}$ and lateral for the carotid arteries, and Townes and lateral projections for the vertebral arteries.

During the examination, the departmental protocol was used for measurement and characterisation of aneurysms. The technique entailed three measurements with the aneurysm in profile, that is, largest axial diameter, largest longitudinal diameter and aneurysm neck diameter at its origin from the parent vessel were measured, as depicted in Figure 2 and Figure 3.

The transverse diameter was the maximal axial aneurysm size, and the longitudinal diameter was measured from the midpoint of the aneurysm neck to the aneurysm dome.
For the purpose of the study, the maximum mean aneurysm sizes (largest transverse or longitudinal diameter) were rounded to the first decimal and classified as $<3 \mathrm{~mm}, \geq 3 \mathrm{~mm}$ to $<7 \mathrm{~mm}, \geq 7 \mathrm{~mm}$ to $<10 \mathrm{~mm}$ or $\geq 10 \mathrm{~mm}$. Aneurysm size (largest transverse diameter) to neck ratio was divided into two groups, narrow $(\leq 50 \%)$ and wide $(>50 \%)$.

Further characterisation included identification of the vessel from which an aneurysm originated. These vessels were grouped as anterior circulation or posterior circulation. In cases of multiple aneurysms, the one in closest proximity to the site of maximal $\mathrm{SAH}$, irregular margins or regional vasospasm was selected.

Anterior circulation vessels included the intracranial internal carotid arteries, and anterior and middle cerebral arteries, including distal branches. Posterior circulation vessels included posterior communicating arteries, posterior cerebral arteries, vertebral and basilar arteries including distal branches.

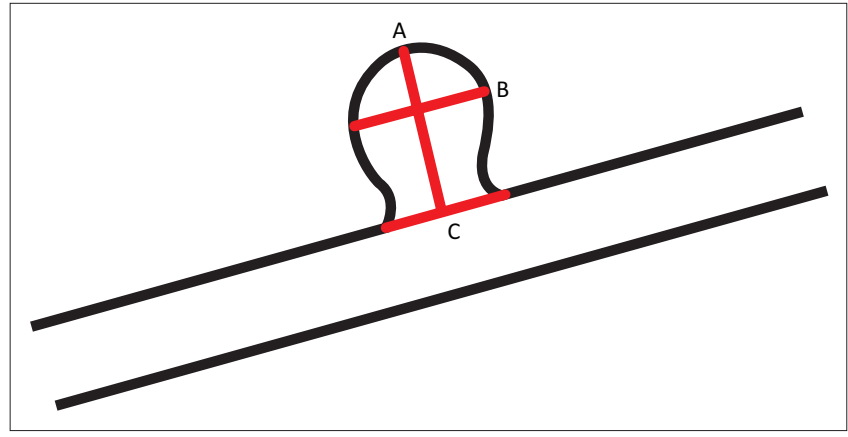

FIGURE 2: Measurement of aneurysms in profile: longitudinal diamete (a) transverse diameter; (b) aneurysm neck (c) at its origin from the parent vessel.
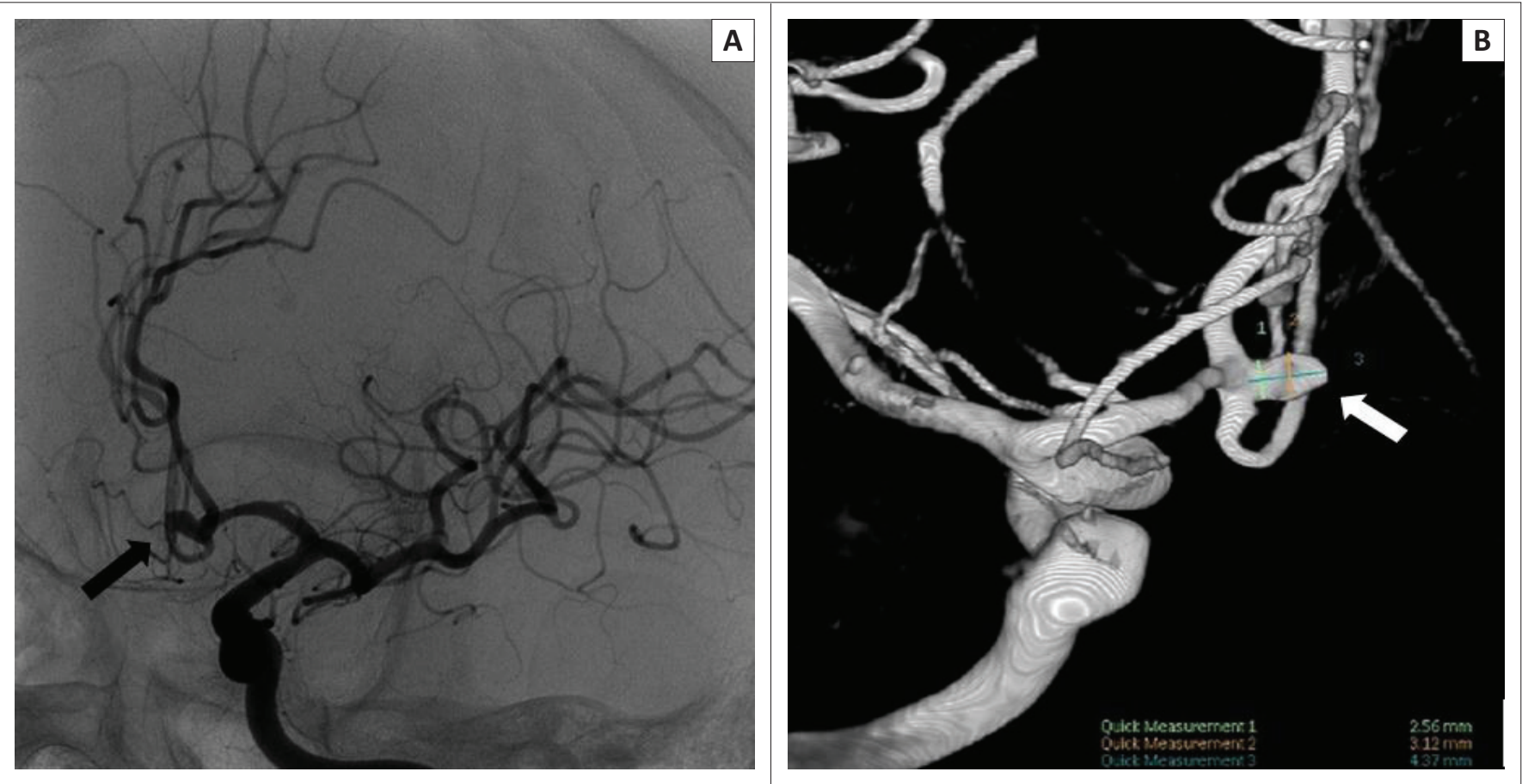

FIGURE 3: (a) Digital subtraction angiography following left internal carotid artery injection demonstrating an anterior communicating artery aneurysm (black arrow); (b) Three-dimensional screensaver image with measurement of an aneurysm and neck size (white arrow). The aneurysm was not amenable to endovascular treatment, because of its wide neck. 
Statistical analysis was carried out with the assistance of the Department of Biostatistics, University of the Free State, using the SAS system (Version 9.3).

Categorical data were summarised by frequencies and percentages. Results for aneurysm size, aneurysm size to neck ratio and patient age were summarised by means and standard deviations or percentiles. Statistical analyses were performed using unpaired $t$-test. The $p$-value $<0.05$ was considered significant.

\section{Results}

A total of 374 patients underwent cerebral DSA over the 6-year period. Of these, 161 had ruptured aneurysms. The remaining 213 patients were excluded from the study because the procedure was performed for indications other than aneurysm-related SAH (e.g. follow-up angiography for assessment of previously noted aneurysms, assessment of incidentally found unruptured aneurysms and assessment of arteriovenous malformations) or was performed as part of the diagnostic workup for spontaneous SAH, with no aneurysms found.

Most of the patients were women (63.4\%). Patient ages ranged from 18 to 73 years, with a mean age of 45 years.

Figure 4 shows the percentage of ruptured aneurysms grouped by size. The overall mean maximal aneurysm size was $5.8 \mathrm{~mm}$ (range between $1.2 \mathrm{~mm}$ and $20 \mathrm{~mm}$ ). In the anterior circulation, the mean size was $5.6 \mathrm{~mm}$, ranging between $1.2 \mathrm{~mm}$ and $20 \mathrm{~mm}$. Aneurysms in the posterior circulation were slightly larger, but not statistically different,

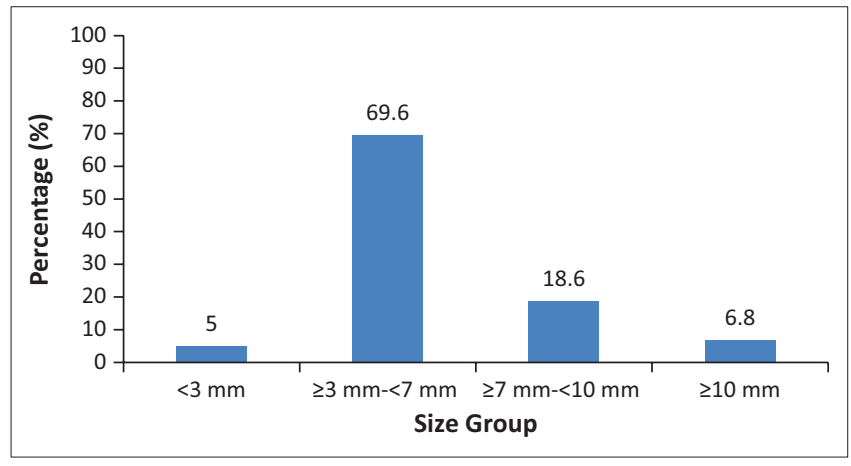

FIGURE 4: Percentage of aneurysms grouped by size $(n=161)$. with a mean size of $6.4 \mathrm{~mm}$ and range from $1.9 \mathrm{~mm}$ to $15 \mathrm{~mm}$ $(p=0.09)$. The mean transverse size of aneurysms was 4.6 $\mathrm{mm}$ (range between 1 and $20 \mathrm{~mm}$ ), and the mean longitudinal size of aneurysms was $5.5 \mathrm{~mm}$ (range between $1.1 \mathrm{~mm}$ and 20 $\mathrm{mm})$. Seventy-five percent of aneurysms were $<7 \mathrm{~mm}$. Slightly more than half of aneurysms (54\%) had a wide neck, whereas $46 \%$ had a narrow neck.

Most aneurysms were noted to involve the anterior circulation $(72 \%)$ with the remainder in the posterior circulation $(28 \%)$. Figure 5 shows the location of aneurysms in major intracranial arteries. Furthermore, $76 \%$ of anterior circulation aneurysms were $<7 \mathrm{~mm}$, as shown in Table 1 .

\section{Discussion}

Aneurysms in North American, European and Asian populations have been widely studied and reported in the literature ${ }^{1,12}$ but little is known about aneurysm characteristics in African populations. The ISUIA published in 2003 concluded that the annual risk of rupture in intracranial aneurysms $<7 \mathrm{~mm}$ in size and occurring in the anterior circulation was $0.1 \%$ in patients with no previous haemorrhage history. ${ }^{2}$ Studies similar to that of ISUIA, however, dispute this finding and cite annual rupture risks between $0.5 \%$ and $2.7 \% .5,6$

Wiebers et al. found that aneurysms $\geq 7 \mathrm{~mm}$ have a considerably increased risk of rupture and, thus, concluded

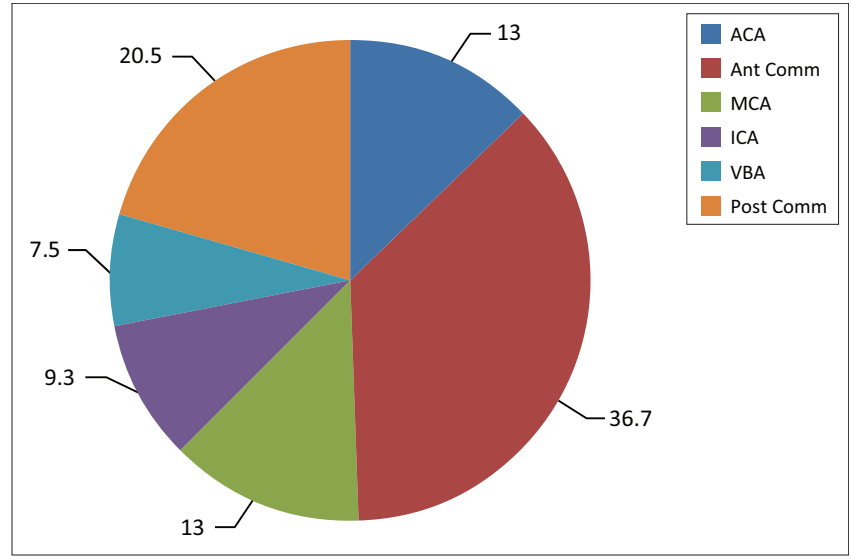

ACA, anterior cerebral artery; Ant Comm, anterior communicating artery; ICA, internal carotid artery; MCA, middle cerebral artery; Post Comm, posterior communicating artery; VBA, vertebral and basilar arteries.

FIGURE 5: Location of aneurysms involving major intracranial arteries (\%).

TABLE 1: Location of aneurysms by main vascular circulation and main vessels.

\begin{tabular}{|c|c|c|c|c|c|c|}
\hline \multirow{2}{*}{$\begin{array}{l}\text { Main vascular locations } \\
\text { grouped by size }\end{array}$} & \multirow[t]{2}{*}{ Variable } & \multirow[t]{2}{*}{$N$} & \multicolumn{2}{|c|}{$<7 \mathrm{~mm}$} & \multicolumn{2}{|c|}{$\geq 7 \mathrm{~mm}$} \\
\hline & & & $n$ & $\%$ & $n$ & $\%$ \\
\hline \multirow[t]{2}{*}{ Main circulation } & ANT & 116 & 88 & 76 & 28 & 24 \\
\hline & POST & 45 & 32 & 71 & 13 & 29 \\
\hline \multirow[t]{6}{*}{ Main vessels } & Ant Comm & 59 & 47 & 80 & 12 & 20 \\
\hline & Post Comm & 33 & 23 & 70 & 10 & 30 \\
\hline & ACA & 21 & 17 & 81 & 4 & 19 \\
\hline & ICA & 15 & 9 & 60 & 6 & 40 \\
\hline & MCA & 21 & 15 & 71 & 6 & 29 \\
\hline & VBA & 12 & 9 & 75 & 3 & 25 \\
\hline
\end{tabular}

ACA, anterior cerebral artery; Ant Comm, anterior communicating artery; ANT, anterior circulation; ICA, internal carotid artery; MCA, middle cerebral artery; $n$, number; POST, posterior circulation; Post Comm, posterior communicating artery; VBA, vertebral and basilar arteries. 
that $7 \mathrm{~mm}$ should be used as the cut-off for considering treatment for these unruptured aneurysms, in the absence of other aneurysm characteristics indicating increased risk of rupture. ${ }^{2}$

Recent guidelines published by the European Stroke Organisation and American Heart Association/American Stroke Association subdivide risk factors for aneurysms as follows: risk factors for aneurysm formation, risk factors for aneurysm growth and risk factors for aneurysm rupture, with less emphasis on size. , $^{8}$

Risk factors for aneurysm formation include female gender, cigarette smoking, hypertension, family history of aneurysms (especially first-degree relatives) and familial syndromes such as polycystic kidney disease. Risk factors for aneurysm growth include female gender, increased blood pressure, haemodynamic stress, inflammation and cigarette smoking in particular, which has been found to hasten growth rate. Risk factors for aneurysmal rupture include size and possibly location of aneurysm, aneurysm morphology (i.e. multilobulated, irregular dome), aneurysm growth, cigarette smoking, young patients at diagnosis (increased lifetime risk), prior aneurysmal SAH, excessive alcohol consumption and hypertension. Modifiable risk factors are cigarette smoking, hypertension (high systolic pressure or prolonged untreated hypertension) and excessive alcohol intake. ${ }^{8,9}$

Multiple single-centre studies reported an overall mean sac diameter of $6.5 \mathrm{~mm}^{13,14}$ and $5.7 \mathrm{~mm}^{15}$ for ruptured aneurysms. Similar population-based studies reported that the majority of ruptured aneurysms are $<5 \mathrm{~mm}$, $^{17,13,16}$ Our retrospective analyses found an overall mean maximum sac diameter of $5.8 \mathrm{~mm}$, with $75 \%$ of ruptured aneurysms $<7 \mathrm{~mm}$. The mean size of aneurysms in the anterior circulation was 5.6 and 6.4 $\mathrm{mm}$ in the posterior circulation, with the difference in size not statistically significant. In total, 150 ruptured aneurysms (93.2\%) were $<10 \mathrm{~mm}$ in size. The latter is more than the $84 \%$ found by Orz et al. and comparable to the findings of Lai et al., in which ruptured aneurysms of this size represented $91 \%$ of all ruptured aneurysms. ${ }^{1,3}$

Suggested explanations for the contradictory findings are discussed by Forget et al., who mentioned a decrease in the size of an aneurysm after rupture and that although having a low rupture risk, the higher prevalence of small aneurysms results in a higher overall number of haemorrhages. ${ }^{12}$ However, a recent study by Schneiders et al. compared changes in aneurysm volume before and after rupture and found an increase in size. ${ }^{17}$ This finding is supported by Kotaoka et al.'s study on histology findings of ruptured and unruptured aneurysms, which found no evidence of shrinkage of aneurysms after rupture. . $^{3,14,16}$

This study found that patients with ruptured intracranial aneurysms were predominantly women, which is similar to findings in the international literature. ${ }^{1,7}$ Ruptured aneurysms in our study population, similar to a variety of international studies since ISUIA, predominantly involved the anterior circulation, and anterior communicating artery in particular. ${ }^{1,7,12,16}$

Aneurysm neck to size (largest transverse diameter) ratio is used at our institution to determine the method of treatment those with narrow necks $(<50 \%)$ undergo endovascular coiling, and the remainder, with wide necks $(>50 \%)$, are treated by surgical clipping. Literature on ruptured intracranial aneurysms does not analyse neck to maximum transverse diameter ratio, but only mentions it as a possible factor affecting treatment outcome. ${ }^{2}$

Although not documented in our results, data relating to the risk factors that increase risk of aneurysm rupture, such as cigarette smoking, hypertension, previous personal and family history of aneurysmal SAH, and excessive alcohol consumption, should always be sought and incorporated when calculating the risk of aneurysmal rupture and subsequent management. ${ }^{8,9}$

\section{Limitations}

Limitations of our study are its retrospective design and small study population. Furthermore, data were not available for patients who succumbed before undergoing DSA, patients who were not stable for DSA and patients who underwent surgical treatment based on computed tomography angiographic findings which may have skewed the results. Because this is a study of ruptured intracranial aneurysms, the risk of rupture of unruptured aneurysms cannot be extrapolated from this data.

\section{Recommendations}

A prospective population-based study is needed to create a national database on aneurysm characteristics and other risk factors such as immune status and comorbidities which should also be documented and studied locally, to provide national statistics for comparison to international literature.

\section{Conclusion}

Despite extensive research and advances in treatment options, there is still uncertainty about the way unruptured intracranial aneurysms should be managed. Our study presents single-centre DSA results about mean ruptured aneurysm size, aneurysm neck to size ratio and aneurysm distribution for patients in central South Africa. We found that, on average, aneurysms rupture at smaller sizes and are commonly located in the anterior circulation. These findings differ from findings of large international multicentre studies ${ }^{2}$ but are similar to the findings of recently published singlecentre studies on ruptured intracranial aneurysms.

\section{Acknowledgements}

The authors wish to thank the Clinical Imaging Sciences Department Research Committee Collaborators for their advice and input, Dr E. Loggenberg for clinical advice and 
Prof. G. Joubert of the Department of Biostatistics, who performed the statistical analysis.

\section{Competing interests}

The authors declare that they have no financial or personal relationships, which may have inappropriately influenced them in writing this article.

\section{Authors' contributions}

C.M. was the project leader. A.I.R.S. was responsible for conceptualising the research idea, literature research, data collection, statistical analyses with help from the Department of Biostatistics and preparation of the publication manuscript. C.M. provided clinical input and advice in the write-up. C.S.d.V. was instrumental in providing clinical input and advice in finalising the publication manuscript.

\section{References}

1. Lai HP, Cheng KM, Yu SCH, et al. Size, location, and multiplicity of ruptured intracranial aneurysms in the Hong Kong Chinese population with subarachnoid haemorrhage. Hong Kong Med J. 2009;15:262-266.

2. Wiebers DO, Whisnant JP, Huston J III, et al. Unruptured intracranial aneurysms: Natural history, clinical outcome, and risks of surgical and endovascular treatment. Lancet. 2003;362(9378):103-110. http://dx.doi.org/10.1016/S0140-6736(03)13860-3

3. Orz Y, Alyamany $M$. The impact of size and location on rupture of intracranial aneurysms. Asian J Neurosurg. 2015;10(1):26-31. http://dx.doi.org/10.4103/ 1793-5482.144159

4. McNulty ML, Lee VH. Management of unruptured intracranial aneurysms and arteriovenous malformations. Am J Ther. 2011;18:64-69. http://dx.doi.org/ 10.1097/MJT.0b013e3181e4ddc6

5. Morita A, Fujiwara S, Hahi K, Ohtsu H, Kirino T. Risk of rupture associated with intact cerebral aneurysms in the Japanese population: A systematic review of the literature from Japan. J Neurosurg. 2005;102:601-606. http://dx.doi.org/10.3171/ jns.2005.102.4.0601
6. Juvela S, Porras M, Poussa K. Natural history of unruptured intracranial aneurysms: Probability of and risk factors for aneurysm rupture. J Neurosurg. 2000:93:379-387. http://dx.doi.org/10.3171/jns.2000.93.3.0379

7. Jeong YG, Jung YT, Kim MS, Eun CK, Jang SH. Size and location of ruptured intracranial aneurysms. J Korean Neurosurg Soc. 2009;45:11-15. http://dx.doi. org/10.3340/jkns.2009.45.1.11

8. Steiner T, Juvela S, Unterberg A, Jung C, Forsting M, Rinkel G. European Stroke Organization guidelines for the management of intracranial aneurysms and subarachnoid haemorrhage. Cerebrovasc Dis. 2013:35:93-112. http://dx.doi. org/10.1159/000346087

9. Thompson BG, Brown RD Jr., Amin-Hanjani S, et al. Guidelines for the management of patients with unruptured intracranial aneurysms: A guideline for healthcare professionals from the American Heart Association/American Stroke Association. Stroke. 2015;46:2368-2400. http://dx.doi.org/10.1161/ Stroke Association. Strok

10. Vlak MHM, Rinkel GJE, Greebe P, Algra A. Risk of rupture of an intracrania aneurysm based on patient characteristics: A case-control study. Stroke. 2013;44:1256-1259. http://dx.doi.org/10.1161/STROKEAHA.111.000679

11. Blignaut $\mathrm{G}$, Loggenberg $\mathrm{E}$, de Vries $\mathrm{C}$. The radiological appearance of intracranial aneurysms in adults infected with the human immunodeficiency virus. S Afr J Rad. 2014;18(1);Art. \#586, 1-4.

12. Forget TR, Benitez $R$, Veznedaroglu $E$, et al. A review of size and location of ruptured intracranial aneurysms. Neurosurg. 2001;49(6):1322-1326. http://dx. doi.org/10.1097/00006123-200112000-00006

13. Delgado Almandoz J, Feasse J, Crandall B, et al. Size and location of ruptured intracranial aneurysms in a consecutive series of 588 patients with first-time acute subarachnoid hemorrhage treated endovascularly at a tertiary referral medical subarachnoid hemorrhage treated endovascularly at a tertiary referral medicals center over a 16-year time period. Oral abstract O-008. Abstracts of the SNIS San Diego, CA. J Neurointerv Surg. 2012;4(Suppl 1):A4-A5.

14. Kataoka K, Taneda M, Asai T, Yamada Y. Difference in nature of ruptured and unruptured cerebral aneurysms. Lancet. 2000;355:203. http://dx.doi.org/10. 1016/S0140-6736(99)03881-7

15. Jagadeesan BD, Delgado AJE, Kadkhodayan $Y$, et al. Size and anatomic location of ruptured intracranial aneurysms in patients with single and multiple aneurysms: A retrospective study from a single center. J Neurolnterv Surg. 2014;6:169-174. http://dx.doi.org/10.1136/neurintsurg-2012-010623

16. Roessler K, Cejna M, Zachenhofer I. Aneurysmatic subarachnoidal haemorrhage: Incidence and location of small ruptured cerebral aneurysms - A retrospective population-based study. Wien Klin Wochenschr. 2011;123:444-449. http://dx.doi. org/10.1007/s00508-011-1598-z

17. Schneiders JJ, Marquering HA, Van den Berg R, et al. Rupture-associated changes of cerebral aneurysm geometry: High-resolution $3 D$ imaging before and after rupture. Am J Neuroradiol. 2014;35:1358-1362. http://dx.doi.org/10.3174/ajnr. A3866 